\title{
Future Extremes Temperature: Trends and Changes Assessment over the Mono River Basin, Togo (West Africa)
}

\author{
Lawin Agnidé Emmanuel1, Lamboni Batablinlè̀ ${ }^{2}$, Manirakiza Célestin ${ }^{2}$, Kamou Hodabalo³ \\ ${ }^{1}$ Applied Hydrology Laboratory, University of Abomey-Calavi, Abomey-Calavi, Benin \\ ${ }^{2}$ Institute of Mathematics and Physical Sciences, University of Abomey-Calavi, Abomey-Calavi, Benin \\ ${ }^{3}$ Faculty of Sciences, University of Lomé, Lomé, Togo \\ Email: ewaari@yahoo.fr, lbata1982@yahoo.fr,ma nirakiza_celest@yahoofr,hodabalou@gmail.com
}

How to cite this paper: Emmanuel, L.A., Batablinlè, L., Célestin, M. and Hodabalo, K. (2019) Future Extremes Temperature: Trends and Changes Assessment over the Mono River Basin, Togo (West Africa). Journal of Water Resource and Protection, 11, 82-98.

https://doi.org/10.4236/jwarp.2019.111006

Received: December 5, 2018

Accepted: January 21, 2019

Published: January 24, 2019

Copyright $\odot 2019$ by author(s) and Scientific Research Publishing Inc. This work is licensed under the Creative Commons Attribution International License (CC BY 4.0).

http://creativecommons.org/licenses/by/4.0/

\begin{abstract}
This study assessed the extreme temperatures trends and changes over Mono River Basin under the highest greenhouse gas emission scenario RCP8.5. Simulations of five (5) regional climate models (RCMs) provided by Africa-CORDEX program were selected from the eighth (8) considered. Future trends in temperature percentiles, including extremes, are used to assess changes in the distribution of daily temperature over Mono Basin in Togo. Changes of temperature and Extreme low (high) temperatures from the baseline period 1961-2010 were computed for future (2051-2100). This analysis reveals that in the north of the basin, for the positive trends, the maximum is $0.82^{\circ} \mathrm{C} \cdot$ year $^{-1}$ given by model MPI-ESM2 at Tchamba while the strongest negative change is $0.26^{\circ} \mathrm{C} \cdot$ year $^{-1}$ given by model MIROC at Sotouboua. In the south of the basin, the strongest negative trend is of $0.03^{\circ} \mathrm{C} \cdot$ year $^{-1}$ given by model (A) CNRM-CMA5. The maximum ones of the trends for models-mean are all positive except at Anié. Higher percentiles of minimum and maximum temperature will increase at a greater rate than the lower percentiles during dry and rainy seasons (with differences more pronounced for maximum values) over the north. Concerning future changes, almost all the RCMs predicted an increase of maximum and minimum temperatures over most parts of the Mono Basin, particularly in the north. Finally, results predicted an increase of TX90P (TX10P) and TN90P (TN10P) from 10\% to $45 \%$ ( $13 \%$ to $40 \%$ ) and $0 \%$ to $35 \%$ (12\% Mean value), respectively over Mono Ba$\sin$.
\end{abstract}

\section{Keywords}

Future Extreme Temperatures, Trends, Changes, Mono River Basin, Togo 


\section{Introduction}

A global view of climate change impacts is important to quantify the aggregated effects in a given region since large scale processes can influence driving forces at subregional or mesoscale. Indeed, the detection of the planetary warming trend, attributed to anthropogenic activities, has been presented with greater certainty in the 4th report of the IPCC (2013) [1]. According to this report, the average global temperature will increase and can reach $4.5^{\circ} \mathrm{C}$ by 2100 , the precipitation will change and the extreme events will be increasingly recurring. Furthermore, Lewis and King (2018) [2] in the study on evolution of mean, variance and extremes in the 21st century temperatures have showed that warming of the climate system can result in very large corresponding changes in the occurrence of climate extremes. Temperature extremes may occur due to a shift in the whole distribution, where there is an increase in the entire temperature probability distribution, or to changes in the shape of the distribution, such as an increase in variability causing a widening of the distribution. Several studies [3] [4] [5] show that impacts of climate extremes are mostly depending on the spatial scale considered and vary from a region to another, from country to country and even from one local area to another within the same country. For Africa, many previous studies have investigated extreme events and have showed that changes in extreme temperature and precipitation are contrasting [6] [7] [8].

For the specific case of Togo, according to the report of Republic of Togo [9] floods, drought, late rains, high temperatures and high winds are the major risks in the country. The drought covers the entire territory except for the coastal region which is however facing sea level rise risk. It should be noted that among the latest climatic events, flooding takes precedence over other risks with its share of material damage and loss of life. It is becoming more and more dangerous to the whole country. Activities which are most exposed to these risks are farming, livestock farming, marketing of agricultural products and market gardening [10]. In Togo, while local populations have difficulties adapting to such present-day conditions, the absence of governmental politics that will help to alleviate the consequences of future climate change adds another degree of vulnerability for rural inhabitants.

In this Country, studies of the future impact of climate change on precipitation and temperature are very few. Furthermore, at the Mono River Basin scale which is the major one of Togo, there was no study focuses on future trends of the extreme temperatures. This means that there are no more details for the near and far future about the impact of climate change on Mono River Basin in Togo (West Africa). In recent years, a relatively large number of RCM outputs have been made available, but there is no consensus on the best way to assess their performance [11]. There are several challenges in evaluating RCMs. For example, an RCM might perform well for some variables in some regions but not for other variables. Moreover, even if a climate model performs well under present climate conditions it might not perform equally well under future conditions 
[11]. For these reasons, it is generally recommended to use a multi-model ensemble of RCMs (or GCMs). In this study, temperatures simulated by 8 RCMs from the Africa-CORDEX program have been analyzed through maximum and minimum temperatures and warm days and warms nights on the Mono River Basin which is the major economical part of Togo in terms of agricultural and energy outputs. Regional Climate Models (RCMs) from CORDEX (CO ordinated Regional Climate Downscaling Experiment) are now proposed in our study because of their high spatial resolution (10 to $100 \mathrm{~km}$ ) [8]. The objective of this study is to analyze the future evolution of some extreme temperature over Mono Basin in Togo (West Africa). Regional decision-makers will have the privilege of having the basic elements assessment to guide the policies on adaptation strategies to climate change.

\section{Data and Methods}

\subsection{Study Area}

Located on the coast of the Gulf of Guinea in West Africa, Togo has a surface area of 56,600 $\mathrm{km}^{2}$, bordering the Atlantic Ocean in the south, Burkina Faso in the north, Benin in the east, and Ghana in the west. The Togolese population was estimated at 6.3 million inhabitants in 2007 according to the report of UNDP in 2007. The main important rivers are Oti, Mono, Kara, Keran, Koumongou, Anie, Zio and Haho. Mono Basin, which is the study area, is located in the Gulf of Guinea region, more precisely between $06^{\circ} 16^{\prime} \mathrm{N}$ and $09^{\circ} 20^{\prime} \mathrm{N}$ and $0^{\circ} 42^{\prime} \mathrm{E}$ and $20^{\circ} 25^{\prime} \mathrm{E}$ (Figure 1). The Mono River Basin is almost entirely in Togo although its lower course is between Togo and Benin. Our study considered the part in Togo. It houses a dam of hydroelectric power plant called Nangbeto. Draining a surface of $25,400 \mathrm{~km}^{2}$, the Mono River is the major one of Togo. The climate of the Mono River Basin is the one of West Africa which is controlled by the interaction of two air masses; the influence of which varies throughout the year with the north-south movement of the Intertropical Convergence Zone (ITCZ). Hot and dry continental air masses originating from the high pressure system above the Sahara desert give rise to dusty Harmattan winds over most of West Africa from November to February. In summer, moist equatorial air masses originating over the Atlantic Ocean bring annual monsoon rains [12] [13] [14] [15]. Within this West African context, Mono Basin's climate varies from tropical to savanna. The southern part of the country is humid, with temperatures ranging from $23^{\circ} \mathrm{C}$ to $32^{\circ} \mathrm{C}$. In the north, temperature fluctuations are greater from $18^{\circ} \mathrm{C}$ to more than $38^{\circ} \mathrm{C}$. Rainfall in the south of the country comes in the form of two seasons (the first between April and July and the second between September and November). The dry desert winds of the Hamattan blow south between November and March, bringing cooler, drier weather, and periodic droughts to the north of the basin. According to the report of WAEMU in 2006, the population of the basin is approximately two million, with an annual increase of $2.9 \%$. This population also distributed at high densities in the south 


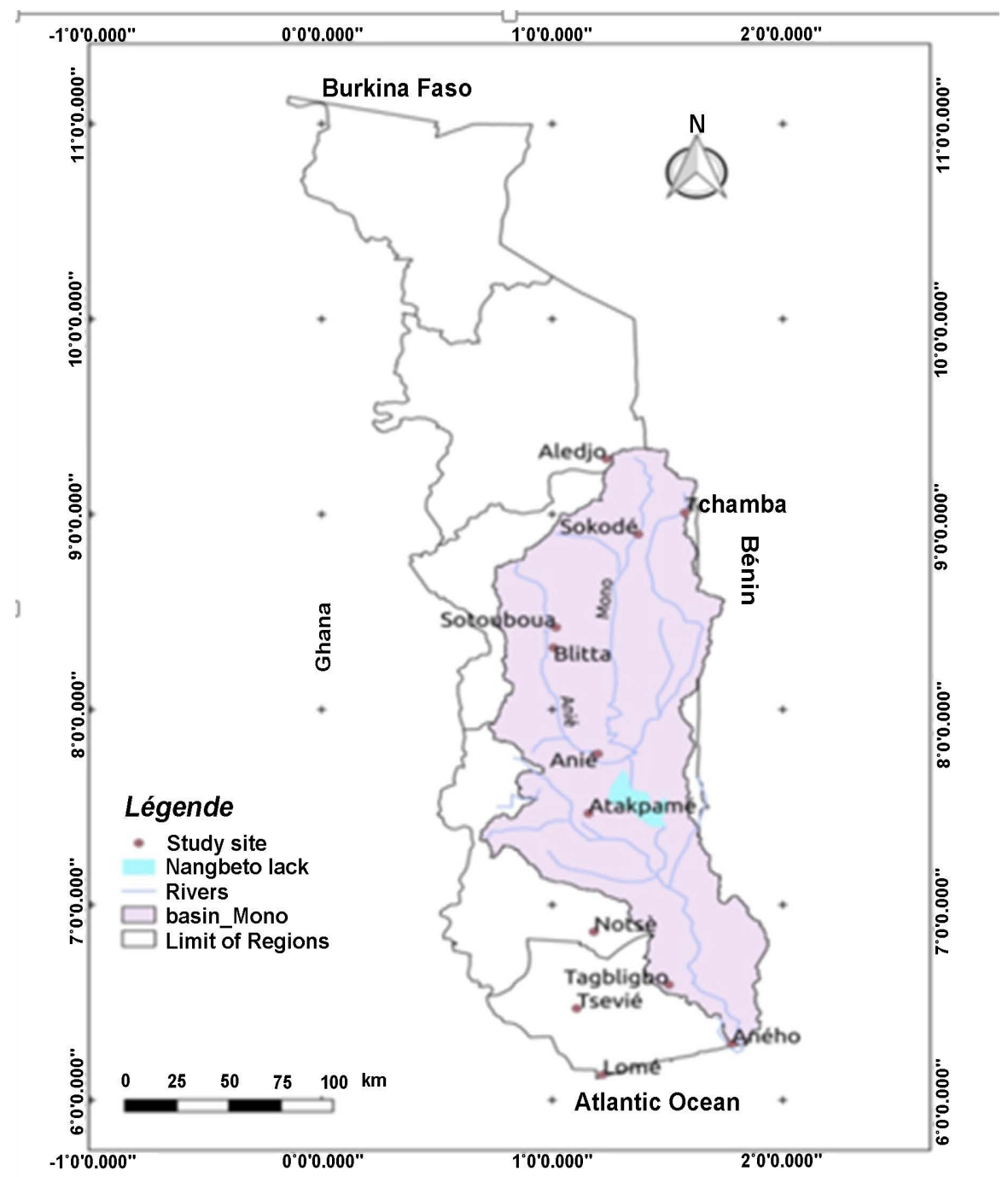

Figure 1. Study area location.

of the basin has as main activities, agriculture (mainly rainfed); in the lower valleys, fishing and salt-farming are the major activities.

\subsection{Data Used}

Two sources of data have been used in this paper. The first one is CORDEX program archives. The CORDEX program archives outputs from a set of RCM simulations over different regions in the world. The CORDEX domains for model integrations are found at

http://wcrpcordex.ipsl.jussieu.fr/images/pdf/cordex_regions.pdf. In this study datasets from CORDEX Africa are accessed from

https://esgf-data.dkrz.de/projects/esgf-dkrz/. The datasets are quality controlled. The spatial grid resolutions of all CORDEX Africa RCMs were set to longitude $0.44^{\circ}$ and latitude $0.44^{\circ}$ using a rotated pole system coordinate. These models operate over an equatorial domain with a quasi-uniform resolution of approximately $50 \mathrm{~km}$ by $50 \mathrm{~km}$. The components of the model are based on the scena- 
rio or Representative Concentration Pathway (RCP). Detailed description of CORDEX RCMs and their dynamics as well as their physical parameterization are given by Nikulin et al. (2018) [16]. Those authors listed the details of CORDEX-RCMs and the driving GCMs: CNRM-CERFACS-CNRM-CM5 (CNRM), ICHEC-EC-EARTH (ICHEC) and MPI-M-MPI-ESM-LR (MPI). Most of them or their precursors are described in detail by Nikulin et al. (2018) [16]. These data have also been used over Mono Basin [8]. Table 1 presents the eight climatic models used with daily time step outputs. The last source of data is the observed temperatures provided by the National Meteorology Agency of Togo (Météo Togo) for the period 1960-2010 for stations spatially located as shown by Figure 1. The data provided by National Meteorology Agency are regridded into a common $50 \mathrm{~km}$ grid.

\subsection{Methods}

Two periods were considered in this study: the reference period (1961-2010) and the future (2051-2100). Trends in temperature percentiles are used to assess changes in the distribution of daily temperature over Mono Basin (including extremes). The 1st, 5th, 10th, 15th, 20th, 25th, 75th, 80th, 85th, 90th, 95th and 99th percentiles of both the daily minimum and daily maximum temperature distributions are estimated on a seasonal basis for every year. Extreme low (high) temperatures are defined by the 1st, 5th, 10th and 15th (85th, 90th, 95th, and 99th) percentiles of the daily minimum and maximum temperature distribution. There are numerous empirical methods that can be used to obtain smooth estimates of the aforementioned percentiles. In thi study these data were calculated using the Climate Data Operator Commands. Then, the free software $\mathrm{R}$ is used to compute all the statistical parameters such as slopes, minimum and maximum and all plots presented in this paper. The models are forced for the future by the scenario RCP8.5 [17]. This scenario corresponds to an emission of $8.5 \mathrm{~W} / \mathrm{m}^{2}$ in 2100 .

Table 1. Used climatic models, global model under which they are run (Column 1), their Institute of origin (Column 2), and their short name (Column 3).

\begin{tabular}{ccc}
\hline Global Model Name & Institute ID & Model Short Name \\
\hline MPI-ESM-LR & MPI-M & MPI \\
MIROC5 & MIROC & MIROC \\
IPSL-CMA5-MR & IPSL & IPSL \\
EC-EARTH & ICHEC & ICHEC \\
CNRM-CM5 & CRNM-CERFACS & CNRM \\
GFDL-ESM2M & NOAA-GFDL & NOAA \\
NorESM1-M & NCC & NCC \\
CanESM2 & CCCMa & CCCMA \\
\hline
\end{tabular}


To bias-correct the model future projection, the cumulative distribution function matching (CD FM) of the model in the reference period is used to identify the corresponding percentile values of the future period [10]. Later the observation CD FM is used to find the climate variable value for the same future cumulative probability, which represents the bias corrected future value. The drawback of the above procedure of bias correction is the assumption of constant bias between the reference and future periods [8]. However, we will accept this assumption as most of the recent studies did [18]. As mentioned earlier, bias correction and spatial disaggregation relies on finer-scale observation data and consists of the following steps:

- Aggregate finer-scale observed data to an RCM-specific scale.

- Correct the RCM's systematic biases through quantile mapping.

- Disaggregate bias-corrected outputs to a finer scale.

An equitation cumulative distribution function matching (equitation CD FM). The description of the algorithm used for the temperatures disaggregation procedure was proposed by Lin et al. (2013) [19]. Observational data were interpolated before calculations. These methods have been used over Mono Basin by Batablinle et al. (2018) [8].

The relative changes from the reference period are assessed as shown by equation below respectively for temperature percentiles $\left(T_{T-P}\right)$ and minimum and maximum temperature $\left(I_{T}\right)$ :

$$
\begin{gathered}
I_{T-P}=\left(\frac{F F-H I S T}{H I S T}\right) \times 100 \\
I_{T}=F F-H I S T
\end{gathered}
$$

where $F F$ and HIST represent respectively the mean for the far future (2051-2100) and the historical or reference period (1961-2010). Before, statistical measures such as the Nash-Sutcliffe Efficiency (NSE), the modified Nash-Sutcliffe coefficient $(\bmod N S E)$ and the volume bias $(V B)$ were used to describe and compare the observed and simulated variables. The validation was performed on eighth RCMs models over the Mono Basin for the period 2001-2010. The criteria are defned as follows:

$$
\begin{gathered}
V_{B}=\frac{\sum_{t=0}^{n}\left(X_{S}-X_{O}\right)}{\sum_{t=0}^{n} X_{S}} \\
N S E=1-\frac{\sum_{t=0}^{n}\left(X_{S}-X_{O}\right)^{2}}{\sum_{t=0}^{n}\left(X_{0}-X_{1}\right)^{2}} \\
\operatorname{ModNSE}=1-\frac{\sum_{t=0}^{n}\left(\left(X_{S}-X_{O}\right) X_{0}\right)^{2}}{\sum_{t=0}^{n}\left(\left(X_{0}-X_{1}\right) X_{0}\right)^{2}}
\end{gathered}
$$


where $X_{o}$ is observed variables, $X_{s}$ simulated variables, $X_{1}$ mean observed variables and $\mathrm{t}$ is time. These methods have been used over Mono Basin by Batablinle et al. (2018) [10]. Among the eight models, statistical results obtained for the validation period showed that there is good agreement between simulated and observed data only for five models such as: IPSL-CMA5-MR, EC-EARTH, MPI-ESM2, CNRM-CMA5 and MIROC which are retained for this study.

\section{Results and Discussions}

\subsection{Trends in Minimum and Maximum Temperature over Mono Basin}

Table 2 and Table 3 present the trends between 2051-2100 of the minimum and maximum temperatures. The calculation of the trend in temperatures was done into two parts. This decomposition makes possible to notice more characteristics which can be masked by the high of the heterogenousness of the climate. Indeed Mono Basin's climate varies from tropical to savanna. The southern part of the country is humid. Rainfall in the south of the country comes in the form of two seasons (the first between April and July and the second between September and November). In northern basin, there is one rainy season extends from April to October.

The first part is based in Northern basin. Table 2 presents the results of the trends for each model and by station. The examination of this Table shows that the trends are null, negative or positive. For the positive trends, the maximum is $0.82^{\circ} \mathrm{C} \cdot$ year $^{-1}$ given by model MPI-ESM2 at Tchamba. The null trends are presented by model CNRM-CMA5 and Mean-models at Sokodé, Tchamba, respectivily. For the negative changes, strongest is $0.26^{\circ} \mathrm{C} \cdot$ year $^{-1}$. In a general way, the trends of temperatures are weakest of positive trends. The modelsIPSL-CMA5-MR and EC-EARTH present trends which are equal for respectively the stations Sotouboua, Sokodé and Tchamba, Alédjo.

The second part is based in Southern basin. The results of this area are present in Table 3. Compared to the southern basin, all the trends are more marked. These trends also evolve between positive and negative values. The strongest negative trend is $0.12^{\circ} \mathrm{C} \cdot$ year $^{-1}$ given by model CNRM-CMA5. The maximum ones of the trends for model-mean are all positive except at Anié.

\subsection{Percentile of Daily Temperature Trends}

Results from this section indicate some significant future changes to the extreme ends of the daily minimum and maximum temperature distributions. In this part, we carried out with a mean of 5 RCMs from Africa-CORDEX program. Changes to the entire probability distribution are analyzed by plotting seasonal trends in the 1st, 5th, 10th, 15th, 20th, 25th, 75th, 80th, 85th, 90th, 95th, and 99th percentiles of daily minimum and maximum values. Seasons are defined as dry season (November-December-January-February-March-April (NDJFMA)), and Rainy season (May-June-July-August-September-October (MJJASO)). As 
Table 2. Minimum and maximum temperatures trends $\left({ }^{\circ} \mathrm{C} \cdot \mathrm{year}^{-1}\right)$ per model and for each season between 2011-2100 under Scenario RCP8.5 over Mono River Basin.

\begin{tabular}{ccccccccc}
\hline Model Name & \multicolumn{2}{c}{ Sokodé } & \multicolumn{2}{c}{ Sotouboua } & \multicolumn{2}{c}{ Tchamba } & \multicolumn{2}{c}{ Alédjo } \\
\hline & $\operatorname{Tmax}^{*}$ & $\operatorname{Tmin}^{* *}$ & $\operatorname{Tmax}^{*}$ & $\mathrm{Tmin}^{* *}$ & $\operatorname{Tmax}^{*}$ & $\mathrm{Tmin}^{* *}$ & $\mathrm{Tmax}^{*}$ & $\mathrm{Tm}^{* *}$ \\
\hline MPI-ESM-LR & 0.02 & 0.01 & 0.03 & 0.28 & 0.82 & 0.58 & 0.15 & 0.18 \\
MIROC5 & -0.05 & 0.015 & 0.08 & -0.26 & 0.61 & 0.15 & 0.32 & 0.2 .2 \\
IPSL-CMA5-MR & 0.02 & 0.01 & 0.02 & 0.01 & 0.15 & 0.52 & 0.18 & 0.31 \\
EC-EARTH & 0.25 & 0.05 & 0.05 & 0.15 & 0.15 & 0.25 & 0.15 & 0.25 \\
CNRM-CM5 & 0.12 & 0.00 & 0.12 & 0.01 & -0.11 & 0.15 & 0.13 & 0.13 \\
Model-Mean & 0.01 & 0.012 & 0.01 & 0.011 & 0.00 & 0.18 & 0.12 & 0.18 \\
\hline
\end{tabular}

${ }^{\star}$ Tmax: Maximum temperature; ${ }^{*}$ Tmin: Minimum temperature.

Table 3. Minimum and maximum temperatures trends $\left({ }^{\circ} \mathrm{C} \cdot \mathrm{year}^{-1}\right)$ per model and for each season between 2011-2100 under Scenario RCP8.5 over Mono River Basin.

\begin{tabular}{ccccccccc}
\hline Model Name & \multicolumn{2}{c}{ Anié } & \multicolumn{2}{c}{ Atakpamé } & \multicolumn{2}{c}{ Tabligbo } & \multicolumn{2}{c}{ Notsé } \\
\hline & $\operatorname{Tmax}^{*}$ & $\operatorname{Tmin}^{* *}$ & $\operatorname{Tmax}^{*}$ & $\operatorname{Tmin}^{* *}$ & $\operatorname{Tmax}^{*}$ & $\operatorname{Tmin}^{* *}$ & $\operatorname{Tmax}^{*}$ & $\operatorname{Tm}^{* *}$ \\
\hline MPI-ESM-LR & 0.2 & 0.2 & 0.31 & 0.13 & -0.15 & 0.18 & 0.15 & 0.28 \\
MIROC5 & 0.25 & 0.015 & 0.08 & 0.25 & 0.6 & 0.05 & 0.13 & 0.22 \\
IPSL-CMA5-MR & 0.02 & 0.15 & 0.02 & 0.5 & 0.25 & 0.5 & 0.08 & 0.38 \\
EC-EARTH & 0.025 & 0.5 & 0.08 & 0.11 & 0.13 & 0.02 & 0.18 & 0.13 \\
CNRM-CM5 & -0.02 & 0.5 & 0.32 & -0.03 & 0.01 & 0.05 & 0.13 & -0.12 \\
Model-Mean & 0.32 & -0.12 & 0.31 & 0.03 & 0.05 & 0.28 & 0.02 & 0.19 \\
\hline
\end{tabular}

${ }^{\star}$ Tmax: Maximum temperature; ${ }^{*}$ Tmin: Minimum temperature.

mentioned earlier, because of previously outlined regional differences between Northtern and Southern Basin, average trends from 2051 to 2100 are separated into southern and Northern areas. The plots in Figure 2 reveal considerable information regarding future trends and changes to the distribution of daily temperature. Over the North, higher percentiles of minimum and maximum temperature will increase at a greater rate than the lower percentiles during dry and rainy seasons (with differences more pronounced for maximum values). This is associated with significant increase in maximum and minimum temperatures over most parts of the Mono Basin. Unlike the North, lower percentiles will increase at a greater rate than the higher percentiles over south basin for minimum temperature. In fact, the lower percentiles of daily maximum temperature during all seasons show relatively increase while the higher percentiles of daily minimum temperature will increase at a greater rate than the lower percentiles during dry and rainy seasons in this area.

\subsection{Changes in Minimum and Maximum Temperature over Mono Basin}

Predicted changes of maximum temperature and minimum temperature between the far future (2051-2100) and the reference period (1961-2010) are shown by Figure 3 and Figure 4, respectively. 

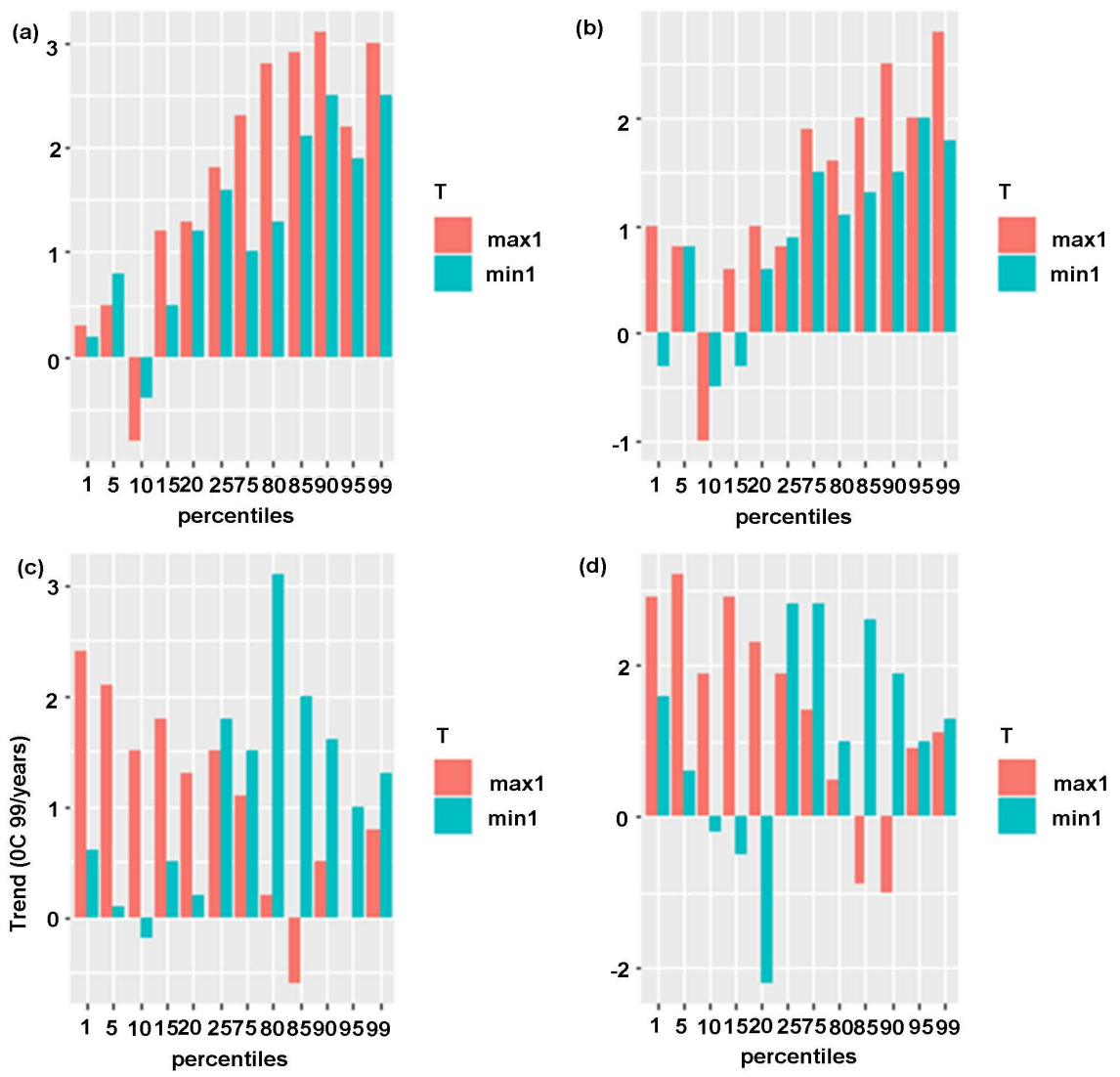

Figure 2. Seasonal trends in various percentiles of daily minimum and maximum temperature over south (c)-(d) and North (a)-(b) Mono Basin from 2051 to 2100.
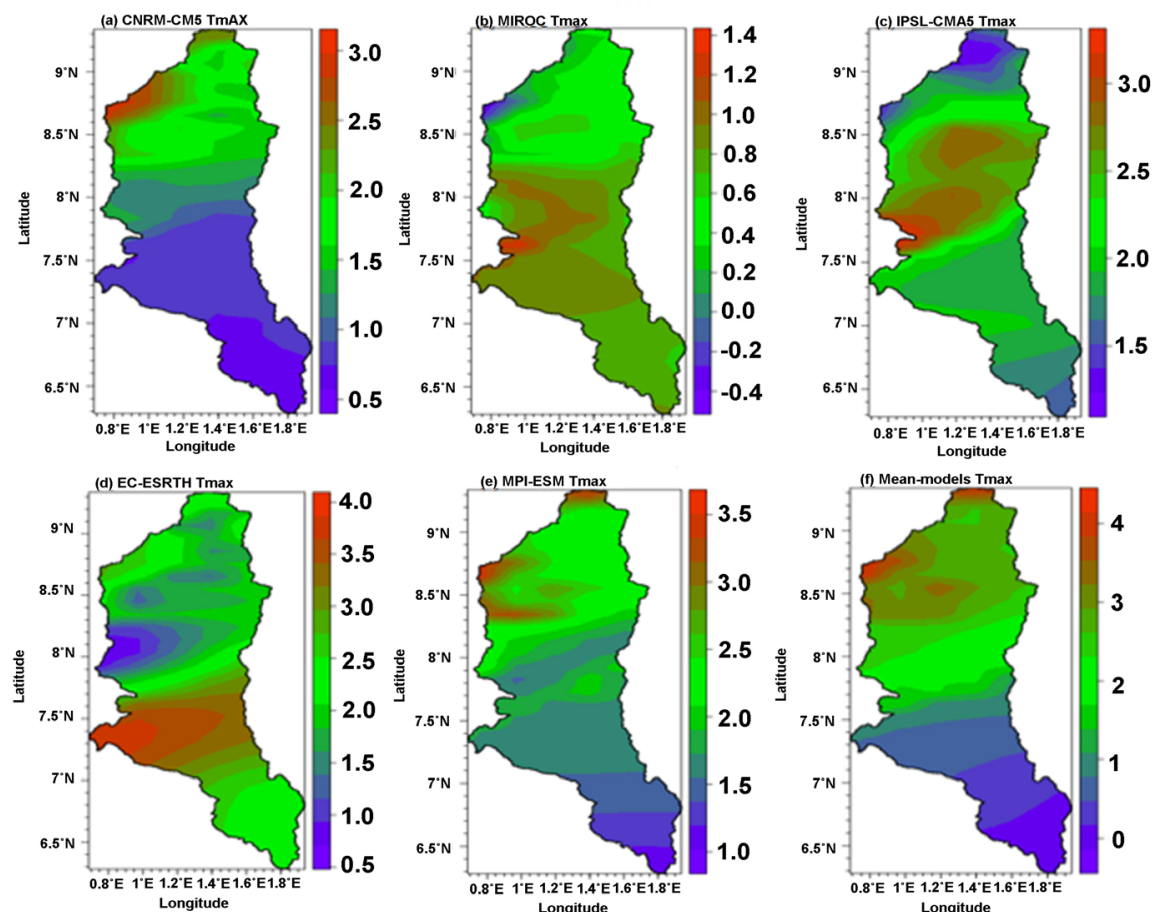

Figure 3. Maximum temperature changes $\left({ }^{\circ} \mathrm{C}\right)$ between future (2051-2100) and historical period (1961-2010) over the Mono Basin. 

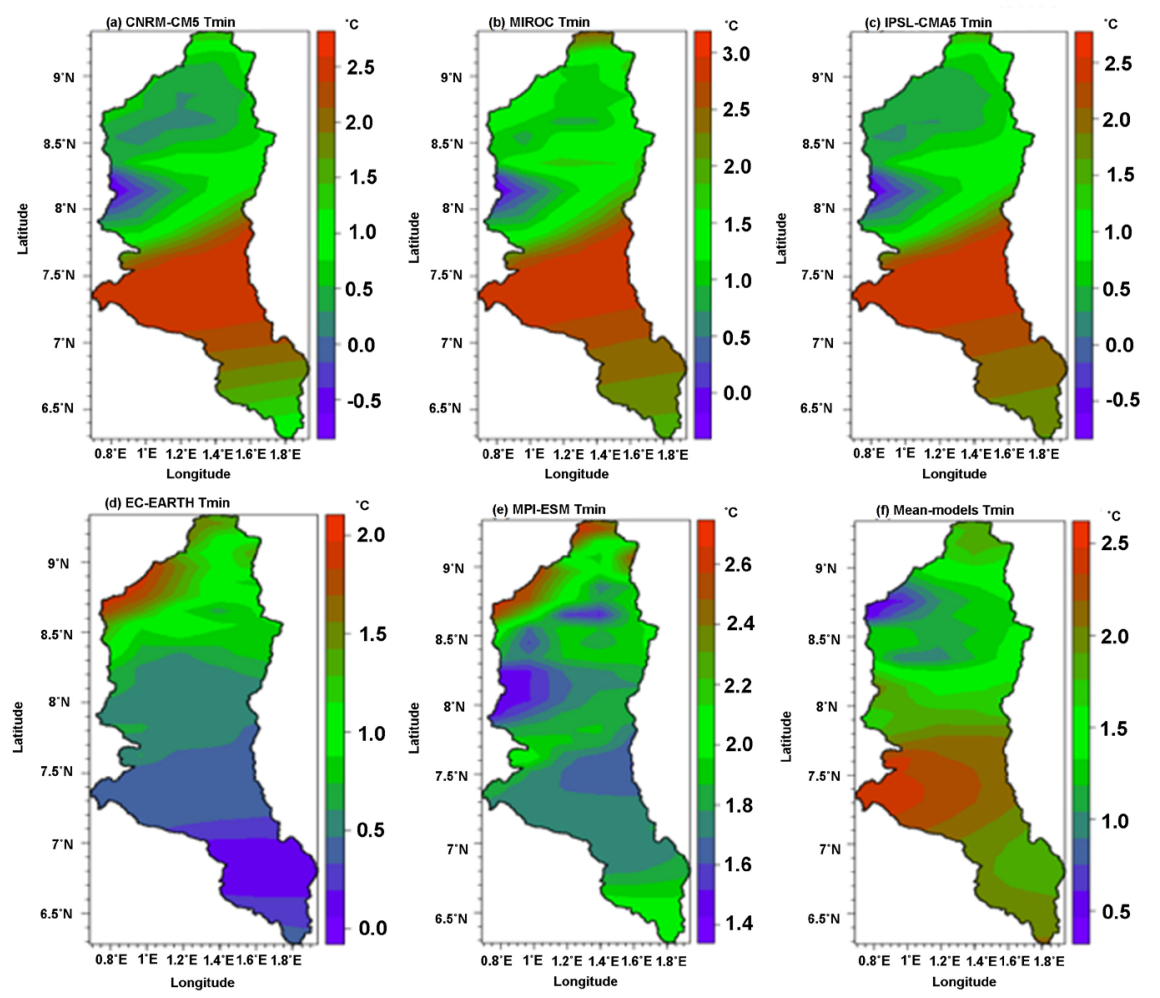

Figure 4. Minimum temperature changes $\left({ }^{\circ} \mathrm{C}\right)$ between far future (2051-2100) and historical period (1961-2010) over the Mono Basin.

For the maximum temperature, all the models predicted an increase for the whole basin except model can ESM2 (Figure 3(f)) which showed a slight decrease for a small part of the southern basin. The lowest increase is $1.4^{\circ} \mathrm{C}$ and is projected by the model MIROC5 (Figure 3(b)). The highest increase is $3.5^{\circ} \mathrm{C}$ and is projected by the rest of models. The north of the basin is forecasted to experience the greatest increase according to almost all the models. The projections exhibited clearly an increase in days of high heat in the north as shown by the models CNRM-CM5 (Figure 3(a)) (mean value $2^{\circ} \mathrm{C}$ ), Mean-Models (Figure $3(\mathrm{f})$ ) (mean value $2^{\circ} \mathrm{C}$ ), IPSL-CMA5 (Figure $3(\mathrm{f})$ ) (mean value $2.5^{\circ} \mathrm{C}$ ), EC-EARTH (Figure 3(d)) (mean value $2^{\circ} \mathrm{C}$ ), MPI-ESM-LR (Figure 3(e)) (mean value $2^{\circ} \mathrm{C}$ ). However, for model MIROC5 (Figure $3(\mathrm{~b})$ ), the maximum temperature will be relatively cooler on some area in the north of the basin (mean value $-0.3^{\circ} \mathrm{C}$ ) and a strong increase on the rest of this area (mean value $2.5^{\circ} \mathrm{C}$ ). In the southward and the center, the maximum temperature will increase in average by $1^{\circ} \mathrm{C}$ for model CNRM-CM5 (Figure 3(a)) and model MPI-ESM-LR (Figure $3(\mathrm{e})), 0.2^{\circ} \mathrm{C}$ for model Mean-Models (Figure $3(\mathrm{f})$ ), $1.5^{\circ} \mathrm{C}$ for models IPSL-CMA5 (Figure 3(c)), EC-EARTH (Figure 3(d)). Globally, the Models-Mean (Figure $3(\mathrm{f}))$ predicted $1.5^{\circ} \mathrm{C}$ as rate of increase.

The analysis of projected minimum temperature for far future revealed that there is a relative uniform evolution over the entire study period for all models except models CNRM-CM5 (Figure 4(a)) and IPSL-CMA5 (Figure 4(c)). Indeed, in the northward, the minimum temperature were projected and will in- 
crease for (mean value $1.5^{\circ} \mathrm{C}$ ), (mean value $1.5^{\circ} \mathrm{C}$ ), (mean value $2^{\circ} \mathrm{C}$ ) and (mean value $1.5^{\circ} \mathrm{C}$ ), respectively, for models MIROC5 (Figure 4(b)), EC-EARTH (Figure 4(d)), MPI-ESM-LR (Figure 4(e)) and Mean-Models (Figure 4(f)). For the models CNRM-CM5 (Figure 4(a)) and IPSL-CMA5 (Figure 4(c)), the results exhibit a decreasing average for the minimum temperature on some area (mean value $-0.5^{\circ} \mathrm{C}$ ) and an increase on the rest in the north (Figure 4). When considering the southward and the center, models used predict an increasing average for, (mean value $2.5^{\circ} \mathrm{C}$ ), (mean value $0.5^{\circ} \mathrm{C}$ ), (mean value $1.8^{\circ} \mathrm{C}$ ), (mean value $2^{\circ} \mathrm{C}$ ), (mean value $1.2^{\circ} \mathrm{C}$ ), (mean value $1.5^{\circ} \mathrm{C}$ ) and (mean value $\left.1.8^{\circ} \mathrm{C}\right)$ ), respectively, for models MIROC5 (Figure 4(b)), EC-EARTH (Figure 4(d)), MPI-ESM-LR (Figure 4(e)) and Mean-Models (Figure 4(f)). While for models CNRM-CM5 (Figure 4(a)) and (C) IPSL-CMA5 (Figure 4(c)), the results show a relative rise of the minimum temperature but more than $1^{\circ} \mathrm{C}$.

\subsection{Changes in TX90P and TN90P over Mono Basin}

For this section, two different extremes were defined on the basis of minimum and maximum temperature separately. TX90P correspond to days with Tx exceeding the daily 90th percentile of its distribution. TN90P are recorded when Tn exceeds the 90th percentile of its own distribution. TN90P and TX90P are percentile based indicators. All of them give information how frequently extreme events occur. The map plots in Figure 5 and Figure 6 sum up the degree of relative changes of the 90th percentile of daily minimum temperature and the 90th percentile of daily maximum temperature between the future (2051-2100) and the historical (1961-2010) periods for the multi-models forced by RCP8.5 greenhouse gas scenarios over Mono Basin.

The 90th percentile of daily maximum temperature changes are presented in Figure 5. As mentioned earlier, Tx 90 represents the number of days where $\mathrm{Tx}$ is greater than the 90th percentile of the daily maximum temperatures occurring during the base period. Almost of all models showed positive changes, revealing a general tendency for warmer days that have connected the rise in the mean global temperature with increases of $\mathrm{Tx}$, which caused an increase of TX90P. The lowest is projected by the model (A) CNRM-CM5 and the model (D) EC-EARTH. The model (A) CNRM-CM5 predicts an increase in 90th percentile of daily maximum temperature ( $\mathrm{Tx} 90$ ) averaging $50 \%$ in the center of the basin, from $0 \%$ to $20 \%$ the southward and a decrease of (mean value $-30 \%$ ) in the northeast while the model (D) EC-EARTH predicts, an increase of the 90th percentile of daily maximum temperature in average from $40 \%$ to $50 \%$ the northward, and southward of the basin a slight decrease from $-5 \%$ to $-10 \%$ is expected. An increase in 90th percentile of daily maximum temperature is projected by the model (B) MIROC up to $35 \%$. This increase is around (mean value $10 \%)$ the southward of basin. The model (E) MPI-ESM predicts, a large increase of TX90P the southward of the basin ranging from $50 \%$ to $60 \%$ against $10 \%$ to $45 \%$ the northward. Concerning the model (C) IPSL-CMA5, the results presented here have suggested, the 90th percentile of daily maximum temperature 

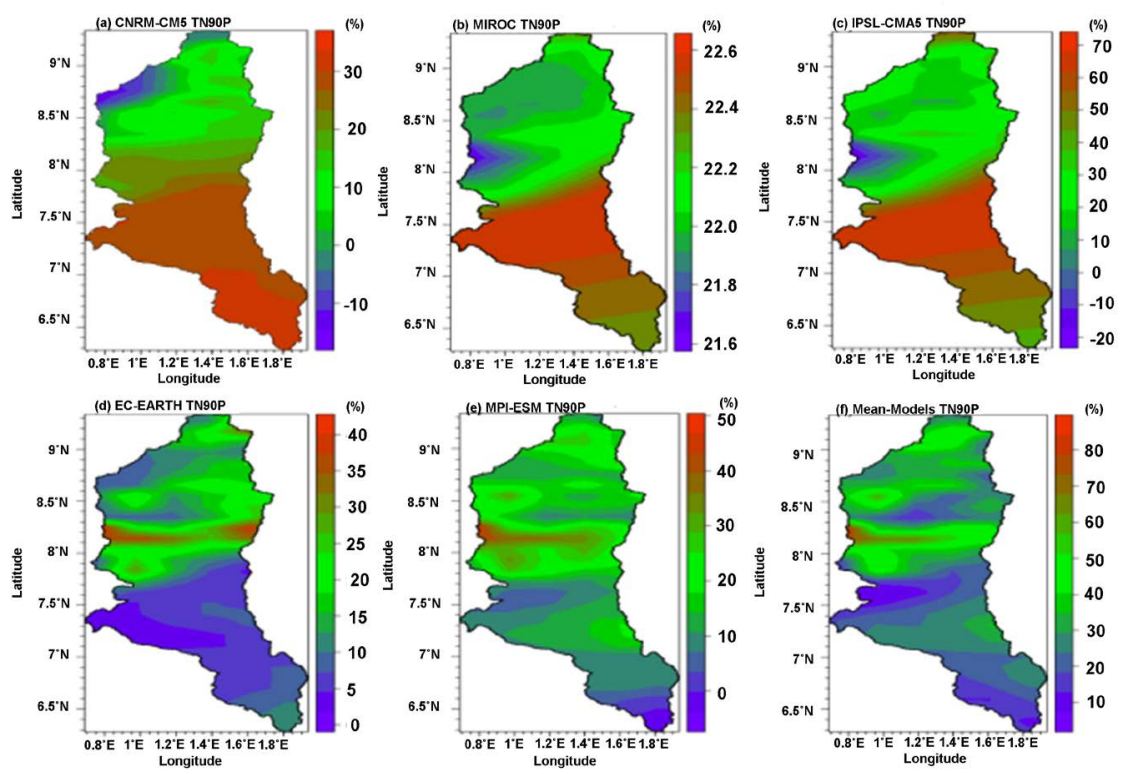

Figure 5. The 90th percentiles of daily maximum temperature changes (\%) between far future (2051-2100) and historical period (1961-2010) over the Mono Basin.
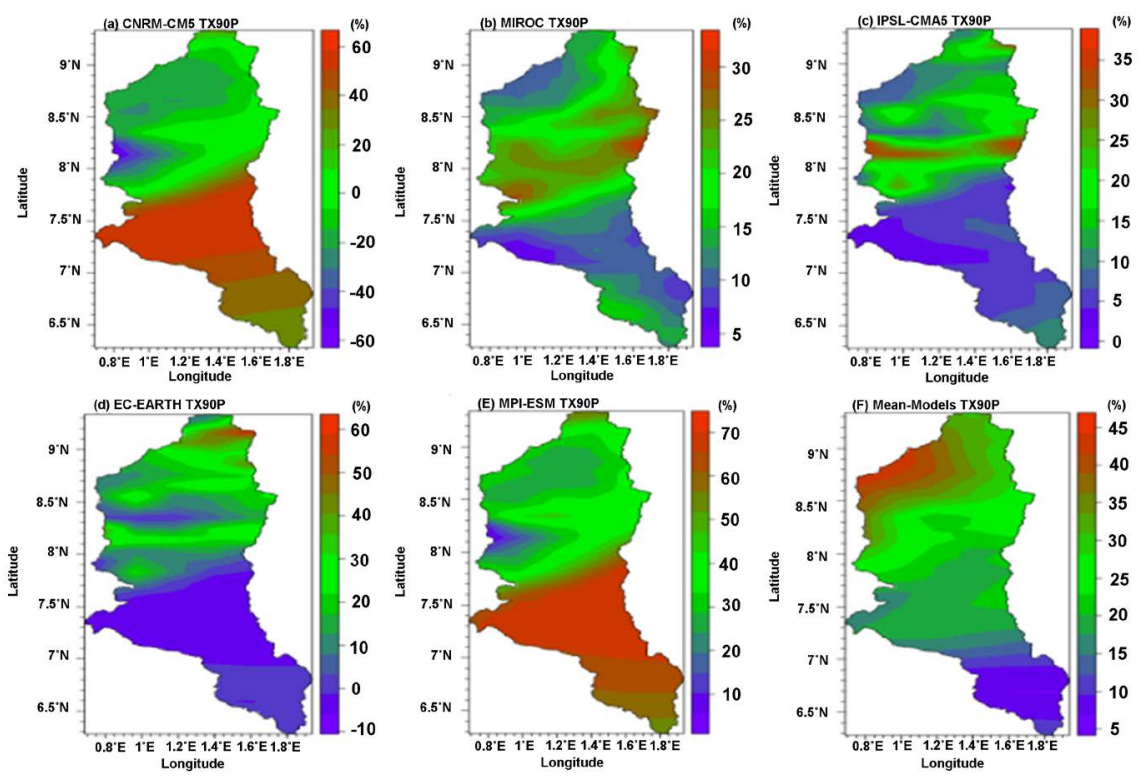

Figure 6. The 90th percentiles of daily minimum temperature changes (\%) between far future (2051-2100) and historical period (1961-2010) over the Mono Basin.

will increase over the entire basin: 5\% northward of the basin and this increase is around $35 \%$ (mean value) in some locality while it is on average from $5 \%$ to $10 \%$ the southward. Finally, the model (F) mean-models project an increase from $20 \%$ to $45 \%$ north of basin against $5 \%$ to $10 \%$ southward.

If we have considered the 90th percentile of daily minimum temperature (TN90P) shown by Figure 6, the lowest is projected by the models (A) CNRM-CMA5 and model (C) IPSL-CMA5. The highest increase is projected by the model (E) MPI-ESM-LR. We note that, the model (A) CNRM-CMA5 pre- 
dicts an increase in TN90P from $25 \%$ to $35 \%$ the southward of the basin, while the northward of the basin will increase of $10 \%$ (mean value). The model (D) EC-EARTH provides an increase in TN90P averaged from 5\% to 50\% over the entire basin. However, the northward of Mono Basin a slight decrease from 0 to $-10 \%$ and $-10 \%$ to $-20 \%$ is expected by model (A) CNRM-CMA5 and model (C) IPSL-CMA5, respectively. The model (B) MIROC show a much larger increase with an average ranging from $20 \%$ to $45 \%$ over Mono Basin. The model (C) IPSL-CMA5 provides an increase in TN90P of $24 \%$ (mean value) over the entire basin, while the models (E) MPI-ESM-LR project an increase from $5 \%$ to $40 \%$ over the entire basin. Finally, the model (F) Mean-Models predicts the increase of TN90P from $10 \%$ to $30 \%$ in the south and $40 \%$ to $60 \%$ in the north of the Mono Basin. The results from this index are consistent with those of the Tx90P, which revealed an increased number of warm days over Mono Basin and show that Warm nights, warm days will become more frequent. These results were not the case for only this study or for Togo, but also for those in coastal countries because of temperature regime caused by the influence of ocean. The report of IPCC (2013) [1], along with previous [7] [20] [21] [22], studies using either GCMs or RCMs, have reported similar results on the amplification of annual and seasonal extreme temperatures over West Africa and in the others region as a response to future anthropogenic climate change.

\subsection{Changes in tx10p and tn10p over Mono Basin}

The relative differences of the 10th percentiles of daily maximum temperature (TX10P) and minimum temperatures (TN10P) between the far future and historical period are shown in Table 4.

The changes relating to the 10th percentile of daily maximum temperature are shown in this Table. The lowest decrease is $-12 \%$ and is projected in the North of Mono Basin by the model IPSL-CMA5 while the highest increase is $50 \%$ and is projected in the center by model MIROC. We note that, the projection models used showed a change of the 10th percentile of daily maximum temperature on the northern part of the basin of 5\%,30\%, 20\%, 15\% and $18 \%$, respectively for models CNRM-CM5, MIROC5, EC-EARTH, IPSL-CMA5, MPI-ESM and Mean-models. The southward and center, there is an increasing average in general for the 10th percentile of daily maximum temperature from $5 \%$ to $45 \%$, and from $15 \%$ to $50 \%$, respectively. Models used have announced clearly an increase over Mono Basin of the 10th percentile of daily maximum temperature.

Contrary to the case of the 10th percentile of daily maximum temperature, the projection models used show in general a decrease and an increase of the 10th percentile of daily minimum temperature. The lowest decrease is $-25 \%$ and is projected in the center of Mono Basin by the model EC-EARTH while the highest increase is $34 \%$ and is projected in the same area by model IPSL-CMA5-M. Indeed, the southward, Northward and center there is an increasing and decreasing average in general of the 10th percentile of daily minimum temperature from $-15 \%$ to $16 \%$, from $-10 \%$ to $23 \%$ and from $-25 \%$ to $34 \%$, respectively. 
Table 4. Summary of mean projected changes (\%) in the 10th percentile of daily minimum (TN10P) and maximum temperature (TX10P) between far future and historical period under Scenario RCP8.5 over Mono River Basin.

\begin{tabular}{ccccccccc}
\hline Model Name & \multicolumn{2}{c}{ North } & \multicolumn{2}{c}{ Center } & \multicolumn{2}{c}{ South } & \multicolumn{2}{c}{ Over-Basin } \\
\hline & TN10P & TX10P & TN10P & TX10P & TN10P & TX10P & TN10P & TX10P \\
\hline MPI-ESM & -10 & 15 & -5 & 15 & 10 & 10 & -2 & 13 \\
MIROC5 & 22 & 30 & -7 & 50 & 16 & 40 & 11 & 40 \\
IPSL-CMA5 & -6 & -12 & 34 & 18 & -7 & 14 & 8 & 14 \\
EC-EARTH & 23 & 20 & -25 & 20 & -15 & 45 & -6 & 35 \\
CNRM-CM5 & 19 & 5 & 23 & 20 & -8 & 15 & 12 & 13 \\
Model-Mean & 15 & 18 & 10 & 15 & 10 & 5 & 12 & 13 \\
\hline
\end{tabular}

The results of this section show that the RCMs and their mean in general projected an increase of the 10th percentile of daily maximum temparure over the Mono Basin. Concerning the 10th percentile of daily minimum temparure, It will go up (excepted models EC-EARTH and MPI-ESM) as shown by change values presented in Table 4. This is consistent with Figure 5 and Figure 6, which show significant increases to the 90th percentile of daily minimum temperature and maximum temperature over most of basin.

The analysis of extreme weather indices shows that all climate projections indicate an overall increase in extreme temperatures while the trends are null negative or positive in the Mono catchment. To have better comprehension of results of in this paper it is important to look at the results of other regions or countries. Despite everything, in the Mono Basin, several models used agree on an increase in temperature (maximum and minimum) and the positive trends on a large part of the basin. Nelson et al. (2010) [13] using models GCM (general circulation models), showed that, in the future (specifically by 2050) the mean temperature is expected to increase between $1{ }^{\circ} \mathrm{C}$ and $2.5^{\circ} \mathrm{C}$ in Togo. Batablinle et al. (2018) [8] using RCMs showed that a decrease is found for the precipitations while monthly-averaged temperature is projected to increase at all horizons considered and under both scenarios (RCP4.5 and RCP8.5) over Mono Basin in Togo. Christidis et al. (2005) [20] point to a significant human influence on the change of extremely hot days and nights, influence related to greenhouse gas emissions. According to the 4th report of the IPCC [1], the average global temperature will increase and could reach $4.5^{\circ} \mathrm{C}$ in 2100 . The dangerous nature of heat waves will be mainly related to the strong increase in minimum and maximum temperatures and the frequency of these events will increase. Meehl et al. (2004) [21] have estimated that these areas of Guinean Africa can expect to experience more intense, more frequent and longer heat waves during the 21st century. Using the RCP8.5 experiment Lewis and King (2017) [2] show that an 
increase in mean temperature throughout the 21st century is a consistent feature of all models for each region. Changes in the variance of simulated temperatures are equivocal, with the magnitude of variance. About the same authors, changes in the 21 st century vary in different models and regions. It is likely that atmospheric circulation variability can explain the observed trends and changes in extremes and will have negative impact over Mono Basin. The influence of other factors such as relationship between soil-moisture deficit and summer hot extremes also needs to be considered in future studies. This temperature's increase will result in reduced fodder yield, an increase in evapotranspiration, a possibility of migration and conflict between livestock and crop farmers as well as in the economical, physical and psychological cost. The contribution of our study in the area is the use of several variables (analyzed with several models) based exclusively on extreme temperatures and other parameters to analyze trends and changes and determine the factors of their temporal variability in the far future. The results of this study could enable policy makers to adapt strategies needed for better management of water and natural disasters and the development of a resilient agricultural system in the face of climate change.

\section{Conclusion}

New multi-model data are used in this paper to analyze trends and changes in extreme temperature events over the Mono Basin in the future (2051-2100) and the historical period (1961-2010). The analysis of these climatic data has contributed to the knowledge of extreme phenomena and their evolution in the future over the Mono Basin. These extreme climatic phenomena are very random and highly variable in space and time. So, their knowledge is therefore fundamental to protect against natural disasters. The RCMs as well as their average show that over the Mono Basin temperatures (maximum and minimum) will increase while the trends are null, negative or positive. We note that higher percentiles of minimum and maximum temperature have increased at areater rate than the lower percentiles during dry and rainy seasons (with differences more pronounced for maximum values) over the north of the basin. The multi-models also predict the increase of TX90P (TX10P) and TN90P (TN10P) from 10\% to $45 \%$ (13\% to $40 \%)$ and $0 \%$ to $35 \%$ (12\% Mean value), respectively over Mono Basin. The results of this study can serve as a reference for further climate research in the country. In short, further work is needed in order to improve the impact assessments of the climate change on water resources and on certain human activities such as agriculture, energy, fisheries and breeding.

\section{Acknowledgements}

We acknowledge the financial support from the Deutscher Akademischer Austausch Dienst (DAAD). We would like also to thank the CORDEX modeling center for sharing the data sets we used in this study. 


\section{Conflicts of Interest}

The authors declare no conflicts of interest regarding the publication of this paper.

\section{References}

[1] IPCC (2013) The Physical Science Basis. Contribution of Working Group I to the Fifth Assessment Report of the Intergovernmental Panel on Climate Change. Intergovernmental Panel on Climate Change 1535.

[2] Lewis, S.C. and King, A.D. (2017) Evolution of Mean, Variance and Extremes in 21st Century Temperatures. Weather and Climate Extremes, 15, 1-10. https://doi.org/10.1016/j.wace.2016.11.002

[3] Diallo, I., Giorgi, F., Deme, A., Tall, M., Mariotti, L. and Gaye, A.T. (2016) Projected Changes of Summer Monsoon Extremes and Hydroclimatic Regimes over West Africa for the Twenty-First Century. Climate Dynamics, 47, 3931-3954. https://doi.org/10.1007/s00382-016-3052-4

[4] Easterling, D.R., Evans, J.L., Groisman, P.Y., Karl, T.R., Kunkel, K.E. and Ambenye, P. (2000) Observed Variability and Trends in Extreme Climate Events: A Brief Review. Bulletin of the American Meteorological Society, 81, 417-425. https://doi.org/10.1175/1520-0477(2000)081<0417:OVATIE >2.3.CO;2

[5] Powell, E.J. and Keim, B.D. (2015) Trends in Daily Temperature and Precipitation Extremes for the Southeastern United States: 1948-2012. Journal of Climate, 28, 1592-1612. https://doi.org/10.1175/JCLI-D-14-00410.1

[6] N'Tcha M'Po, Y., Lawin, A.E., Yao, K.B., Oyerinde, G.T., Attogouinon, A. and Afouda, A.A. (2017) Decreasing Past and Mid-Century Rainfall Indices over the Ouémé River Basin, Benin (West Africa). Climate, 5, 74. https://doi.org/10.3390/cli5030074

[7] Aguilar, E., et al. (2009) Changes in Temperature and Precipitation Extremes in Western Central Africa, Guinea Conakry, and Zimbabwe, 1955-2006. Journal of Geophysical Research, 114, D02115. https://doi.org/10.1029/2008JD011010

[8] Batablinle, L, Lawin, E. and Agnide, S. (2018) Africa-Cordex Simulations Projection of Future Temperature, Precipitation, Frequency and Intensity Indices over Mono Basin in West Africa. Journal of Earth Science and Climatic Change, 9, 490. https://doi.org/10.4172/2157-7617.1000490

[9] Amegadje, M.K. (2007) Profil Environnemental du Togo. Final Report Prepared for the European Commission and the Ordonnateur National du Fonds Européen de Développement. Republic of Togo, Lomé.

[10] Abdulai, J., Gerald, C.N., Timothy, S.T., Robert, Z. and Harold, R.-M. (2013) West African Agriculture and Climate Change. International Food Policy Research Institute. http://dx.doi.org/10.2499/9780896292048

[11] Knutti, R., Furrer, R., Tebaldi, C., Cermak, J. and Meehl, G.A. (2010) Challenges in Combining Projections from Multiple Climate Models. Journal of Climate, 23, 2739-2758. https://doi.org/10.1175/2009JCLI3361.1

[12] Nicholson, S.E. and Webster, P.J. (2007) A Physical Basis for the Interannual Variability of Rainfall in the Sahel. Quarterly Journal of the Royal Meteorological Society, 133, 2065-2084.

[13] Nelson, G.C., Rosegrant, M.W., Palazzo, A., Gray, I., Ingersoll, C., Robertson, R. and Tokgoz, S. (2010) Food Security, Farming, and Climate Change to 2050: Scenarios, Results, Policy Options. International Food Policy Research Institute, Wash- 
ington DC.

[14] Klutse, N.A.B., Sylla, M.B., Diallo, I., Sarr, A. and Dosio, A. (2016) Daily Characteristics of West African Summer Monsoon Precipitation in CORDEX Simulations. Theoretical and Applied Climatology, 123, 369-386. https://doi.org/10.1007/s00704-014-1352-3

[15] Camara, M., Diédhiou, A., Sow, B.A., Diallo, M.D., Diatta, S., Mbaye, I. and Diallo, I. (2013) Analyse de la pluie simulée par les modèles climatiques régionaux de CORDEX en Afrique de l'Ouest. Sécheresse, 24.

[16] Nikulin, G., et al. (2018) The Effects of 1.5 and 2 Degrees of Global Warming on Africa in the CORDEX Ensemble. Environmental Research Letters, 13, Article ID: 065003.

[17] Moss, R., Edmonds, J., Hibbard, K., Manning, M. and Rose, S. (2010) The Next Generation of Scenarios for Climate Change Research and Assessment. Nature, 468, 747-756. https://doi.org/10.1038/nature08823

[18] Sarr, M.A., Seidou, O., Tramblay, Y. and El Adlouni, S. (2015) Comparison of Downscaling Methods for Mean and Extreme Precipitation in Senegal. Journal of Hydrology, 4, 369-385. https://doi.org/10.1016/j.ejrh.2015.06.005

[19] Lin, W. and Wen, C. (2013) A CMIP5 Multimodel Projection of Future Temperature Precipitation and Climatological Drought in China. International Journal of Climatology, 34, 2059-2078.

[20] Christidis, N., Jones, G.S. and Stott, P.A. (2014) Dramatically Increasing Chance of Extremely Hot Summers since the 2003 European Heatwave. Nature Climate Change, 5, 46-50. https://doi.org/10.1038/nclimate2468

[21] Meehl, G.A., Tebaldi, C., Walton, G., Easterling, D. and McDaniel, L. (2009) Relative Increase of Record High Maximum Temperatures Compared with Record Low Minimum Temperatures in the U.S. Geophysical Research Letters, 36, L23701. https://doi.org/10.1029/2009GL040736

[22] GIEC (2013) Résumé à l'intention des décideurs, Changements climatiques: Les éléments scientifiques. Contribution du Groupe de travail I au cinquième Rapport d'evaluation du Groupe d'experts intergouvernemental sur l'evolution du climat. Cambridge University Press, Cambridge, Royaume-Uni et New York. 